\title{
Prevalence of severe early childhood caries and associated socioeconomic and behavioral factors in Xinjiang, China: a cross-sectional study
}

Yan Li', Jibieke Wulaerhan², Yuan Liu', Ayinuer Abudureyimu² and Jin Zhao ${ }^{1 *}$

\begin{abstract}
Background: This study assessed the prevalence and severity of early childhood caries (ECC) and identified socioeconomic and behavioral correlates of the disease in preschool children living in Xinjiang.

Methods: For this cross-sectional survey, 1727 children aged 3-5 years in Xinjiang were randomly recruited using a three-stage cluster sampling procedure. The "dmft" index according to the WHO 1997 criteria was used to assess ECC and severe ECC (S-ECC). A questionnaire was completed by caregivers. Variables included sociodemographic characteristics, dietary and oral hygiene behaviors, and access to dental services. The statistical associations of variables with ECC, S-ECC, and dmft were evaluated by univariate and multiple logistic regression analyses.

Results: The prevalence of ECC was $78.2 \%$ and that of S-ECC was $41.2 \%$; mean dmft scores were $5.61 \pm 3.56$ and 8 . $17 \pm 2.94$, respectively. The prevalence of ECC was significantly higher in children from Ining $(\mathrm{OR} 2.747 ; 95 \% \mathrm{Cl} 2$. 033-3.713), those whose caregivers had caries (OR 1.78; 95\% Cl 1.245-2.547), those with a dental visit in the past (OR 2.023; 95\% Cl 1.429-2.865), and those whose parents had received instructions on oral health care (OR 2.171; $95 \% \mathrm{Cl}$ 1.44-3.272), and increased significantly at age 4 years (OR 2.09; 95\% Cl 1.506-2.901) and 5 years (OR 2.666; $95 \% \mathrm{Cl} 1.855-3.833$ ) and in children who starting tooth brushing at a young age (OR 1.363; 95\% Cl 1.171-1.587), and decreased significantly in children with a more educated mother (OR $0.817 ; 95 \% \mathrm{Cl} 0.688-1)$, those from highincome families (OR $0.667 ; 95 \% \mathrm{Cl} 0.582-0.765)$, those with low consumption of sweets (OR $0.66 ; 95 \% \mathrm{Cl} 0.57-0.763$ ), and those who seldom ate before sleep (OR 0.557; 95\% Cl 0.437-0.712).

Conclusions: ECC and S-ECC remain a serious problem among preschool children in Xinjiang. Caries rates were associated with sociodemographic and behavioral factors, which could be modified by public health strategies, including protection of primary dentition, extension of insurance to cover oral preventive services, improvement of the oral health care system, and public health education.
\end{abstract}

Keywords: Early childhood caries, Related factors, Children, Xinjiang

\footnotetext{
* Correspondence: merryljin@sina.com

'Department of Endodontics, the First Affiliated Hospital of Xinjiang Medical

University, No. 137, Li Yu Shan South Road, Urumqi, Xinjiang Province

830054, China

Full list of author information is available at the end of the article
} 


\section{Background}

Early childhood caries (ECC) remains a major public health problem in preschool children, especially in developing countries, in view of its early onset and high prevalence, as well as the high likelihood of nontreatment [1-4]. ECC impacts on quality of life, increases the risk of caries in the permanent dentition, and promotes inequalities in oral health $[5,6]$. Moreover, the consequences of untreated severe ECC (S-ECC) in young children are more serious than those of caries that develop in adulthood [7]. However, in most cases, ECC can be prevented, controlled, or even resolved if treated appropriately, even in the presence of S-ECC [8, 9]. Prevention of ECC is not only the responsibility of the dental profession but also that of society as a whole $[5,10]$. Therefore, an effective oral health promotion strategy must be based on understanding and assessment of societal and behavioral factors potentially affecting oral health at the population level.

Societal and behavioral risk factors identified to be associated with S-ECC include low socioeconomic status, lack of fluoridation of community water, maternal factors (low education level, caries experience, less oral health knowledge), consumption of sweets, eating before sleep, inadequate dental hygiene behaviors, and lack of dental services [11-15]. These data indicate that S-ECC is concentrated among children from socially disadvantaged families and communities, those of indigenous and minority status, and those resident in less developed regions [11, 14-16].

The Xinjiang Uygur autonomous region is situated in the far northwestern part of Mainland China, and is a multi-ethnic settlement in which Uyghur and Han Chinese are the predominant ethnic groups, constituting approximately $85.4 \%$ of the total population of 2264.3 billion [17]. As a frontier province, Xinjiang is one of the less developed Chinese provinces in terms of economy and health care, where there is a total of 2573 registered dentists (including assistants) and the ratio of registered dentists to population is 1:8800. Oral health assessment and preventive programs have not been adequately implemented as yet, especially in the rural communities, which lack oral health care services [18]. There are very limited data on the prevalence of ECC and its severity among preschool children in this region. The aims of this study were to assess the prevalence and severity of ECC and to evaluate possible socioeconomic and behavioral correlates of the disease in preschool children aged 3-5 years living in Xinjiang.

\section{Methods}

\section{Study population and sample size}

This study was carried out in the rural and urban communities of the main region of Xinjiang. A three-stage stratified sampling method was used to recruit the study sample. In the first stage, a southern city (Kashgar) and a northern city (Ining) were chosen because they contain the largest populations in the Xinjiang region [17] (Additional file 1: Figure. S1). In the second stage, each of the two selected districts was stratified into urban and rural areas, comprising four urban districts and six rural townships in Kashgar and eight urban districts and eight rural townships in Ining. One kindergarten was randomly selected from each urban district and township. In the third stage, three kindergarten classes representing children aged 3,4 , and 5 years were randomly selected from each enrolled kindergarten. The sample size was calculated before initiation of the study assuming a prevalence of ECC of about $60 \%$ (based on an estimate of the prevalence of ECC in the Urumqi region), a margin of error of 5\%, a 95\% confidence level, and a 15\% non-response rate. Accordingly, a sample size of 294 per age group was sought. The study was approved by the ethics committee at the First Affiliated Hospital of Xinjiang Medical University (Reference 20,130,216-103) and was carried out from March 2013 to May 2015.

\section{Clinical examination}

To ensure reliability, four dentists were trained centrally and evaluated 20 children from a kindergarten before performing the examination until the inter-examiner and intra-examiner reliability showed a Kappa agreement of $>0.85$. The children's oral health examinations were performed in the kindergarten nurses' offices with a knee-to-knee posture between 9.30 a.m. and 11.30 a.m. under natural light using disposable dental mirrors and explorers. No radiographs were taken. The " $\mathrm{dmft}$ " index according to the WHO 1997 criteria was used to assess ECC and severe ECC [19]. ECC was defined as the presence of 1 or more decayed, missing, or filled tooth surfaces in any primary tooth in a child aged up to and including 71 months of age. S-ECC was defined as $\geq 1$ decayed, missing or filled smooth surfaces in the primary maxillary anterior teeth or a dmft score $\geq 4$ (age 3 years), $\geq 5$ (age 4 years), or $\geq 6$ years (age 5) [8]. Secondary caries was considered decayed and children suffering enamel hypoplasia were excluded. All examination records were held by the dentists.

\section{Questionnaire survey}

The questionnaire included information on the following: sociodemographic characteristics (region, sex, age, ethnicity, residence, gestational age, family size, parental education level, average annual income, caretaker with cavities), dietary behaviors (feeding history, frequency of sweets consumption, eating before sleep), oral hygiene behaviors (start of tooth brushing, daily brushing frequency, parental supervision of tooth brushing, and 
using fluoride toothpaste), and use of a dental service (dental visit in the past and parents having received oral health care instruction). A questionnaire in the Uygur and Han languages was designed by the research team referencing the guidelines of the American Academy of Pediatric Dentistry and consensus in the current pediatric dental literature $[8,20]$, and was pre-tested for clarity. Two trained Uygur dental students instructed the caregivers on how to complete the questionnaires. Written informed consent was obtained from all caregivers who agreed to participate in the study.

\section{Statistical analysis}

The statistical analysis was performed using SPSS version 21.0 software (IBM Corp., Armonk, NY, USA). The prevalence and mean dmft score were used to determine the extent and severity of ECC and S-ECC in the study population. Associations of variables with $\mathrm{dmft}$ scores were evaluated using the $t$-test and one-way analysis of variance. The $x^{2}$ and $x^{2}$ for trend were used in univariate analyses to assess the differences between the ECC and $\mathrm{S}$-ECC groups. Variables that showed significant associations were included in multiple logistic regression models. A $p$-value of $\leq 0.05$ was considered to be statistically significant.

\section{Results}

Of 1857 children approached, 1727 were enrolled, representing a 93\% response rate. The reasons for nonresponse were refusal to participate (33\%), absence from kindergarten $(50 \%)$, and failure to complete the questionnaire (17\%). The study populations were evenly distributed between boys (52.1\%) and girls (47.9\%). The mean age of the children was $4.19 \pm 0.72$ years. The prevalence of ECC was $78.2 \%(n=1351)$ with a mean $\mathrm{dmft}$ score of $5.61 \pm 3.56$ and that of S-ECC was $41.2 \%(n=711)$ with a mean $\mathrm{dmft}$ score of $8.17 \pm 2.94$. However, $93 \%$ of the children with caries had not received treatment and $98.3 \%$ of the teeth with caries were not filled.

The prevalence and severity of ECC according to sociodemographic characteristics, dietary habits, oral hygiene habits, and use of a dental service are shown in Table 1. Results from the univariate analyses showed that 13 variables, including region $(P<0.001)$, age $(P<$ $0.001)$, a caretaker with cavities $(P<0.001)$, mother's education level $(P<0.001)$, father's education level $(P=$ $0.001)$, average annual income $(P<0.001)$, frequency of sweets consumption $(P<0.001)$, eating before sleep $(P<$ $0.001)$, start of tooth brushing $(P<0.001)$, daily brushing frequency $(P<0.001)$, parental supervision of tooth brushing $(P<0.001)$, a dental visit in the past $(P<0.001)$, and parents having received oral health care instruction $(P=0.004)$ were associated with ECC. Ten variables, including age $(P=0.012)$, a caretaker with cavities $(P<$ $0.001)$, mother's education level $(P<0.001)$, father's education level $(P=0.005)$, average annual income $(P<$ $0.001)$, frequency of sweets consumption $(P<0.001)$, eating before sleep $(P<0.001)$, parental supervision of tooth brushing $(P=0.011)$, a dental visit in the past $(P<0.001)$, and parents having received oral health care instruction $(P<0.001)$ were associated with S-ECC. As expected, the trend of mean dmft was similar in statistical significance to that of ECC.

Thirteen variables identified as being statistically significant in univariate analysis were entered into the logistic regression models. The results showed that the prevalence of ECC was significantly higher in children from Ining (odds ratio [OR] 2.747; 95\% confidence interval [CI] 2.033-3.713), children whose caregivers had caries (OR 1.78; 95\% CI 1.245-2.547), those with a dental visit in the past (OR 2.023; 95\% CI 1.429-2.865), and those whose parents had received oral health care instruction (OR 2.171; 95\% CI 1.44-3.272). Further, the prevalence of ECC increased significantly at the age of 4 years (OR 2.09; 95\% CI 1.506-2.901) and 5 years (OR 2.666; 95\% CI 1.855-3.833) and in those who started tooth brushing at a younger age (OR 1.363; 95\% CI 1.171-1.587), and decreased significantly in children with a more highly educated mother (OR $0.817 ; 95 \% \mathrm{CI}$ $0.688-1$ ), those from a high-income family (OR 0.667; 95\% CI 0.582-0.765), those with low-frequency sweets consumption (OR 0.66; 95\% CI $0.57-0.763$ ), and those who seldom ate before sleep (OR 0.557; 95\% CI $0.437-$ 0.712), as shown in Table 2.

A similar result was found for S-ECC, the prevalence of which was significantly higher in children who had a caregiver with caries (OR 1.827; 95\% CI 1.43-2.334), those with a dental visit in the past (OR 2.253; 95\% CI 1.774-2.861), and those whose parents had received oral health care instruction (OR 1.821; 95\% CI 1.358-2.441). The prevalence of S-ECC was significantly decreased in children from high-income families (OR 0.843; 95\% CI 0.76-0.935), those with a low frequency of sweets consumption (OR 0.842; 95\% CI 0.745-0.939), and those who seldom ate before sleep (OR 0.694; 95\% CI 0.573 0.84 ), but no significant association was found with region, the child's age, the mother's education level, or when the child starting tooth brushing (Table 3).

\section{Discussion}

Our study found high prevalences of ECC and S-ECC (78.2\% and $41.2 \%$, respectively) among preschool children aged 3-5 years who were living in Xinjiang. The prevalence of ECC in this survey was significantly higher than that in children in mainland China overall $(53.6 \%)$ in 2010-2013 [1]. The prevalence of ECC in 5-year-old children $(84.5 \%)$ is not only higher than that in other 


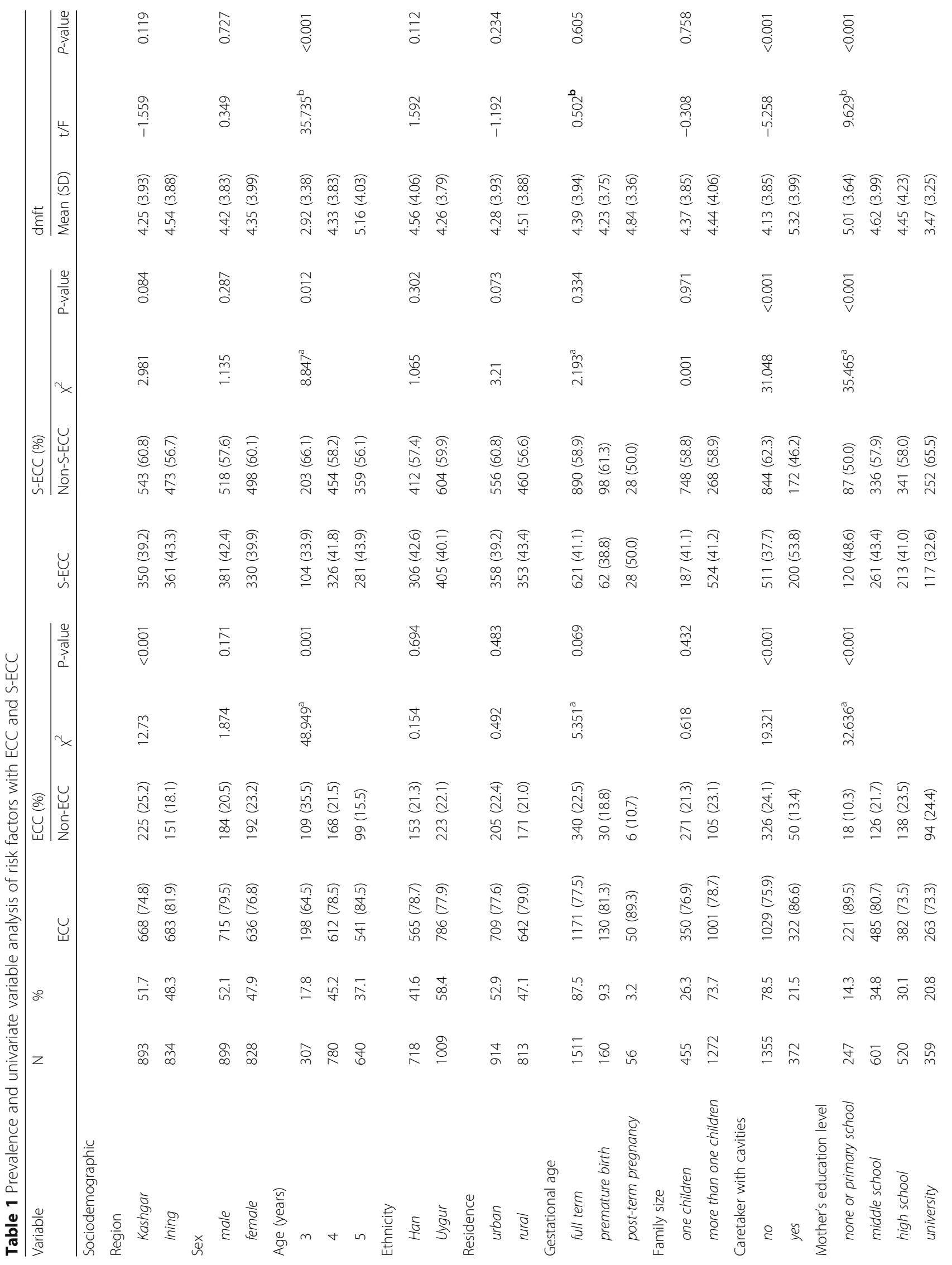




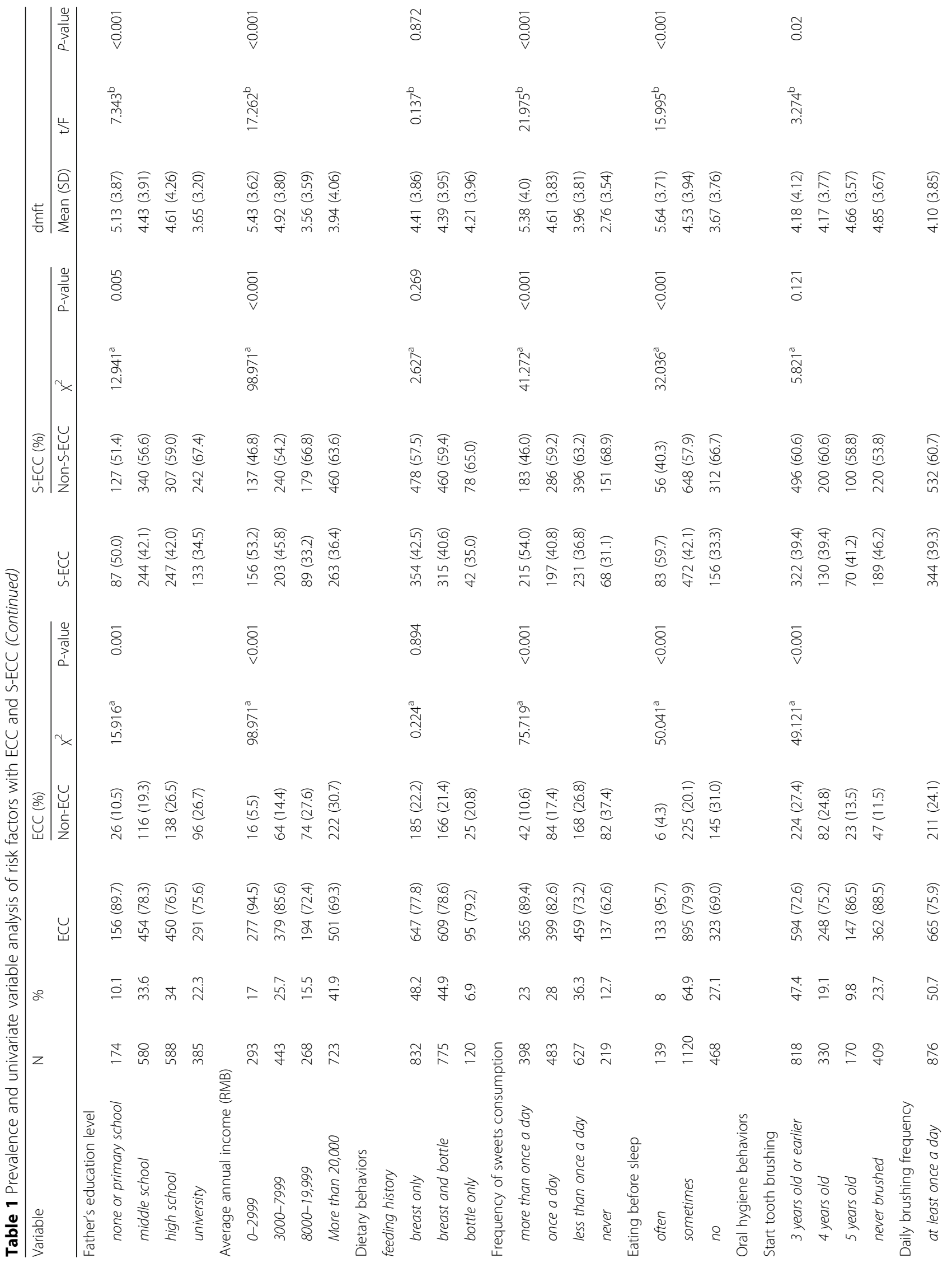




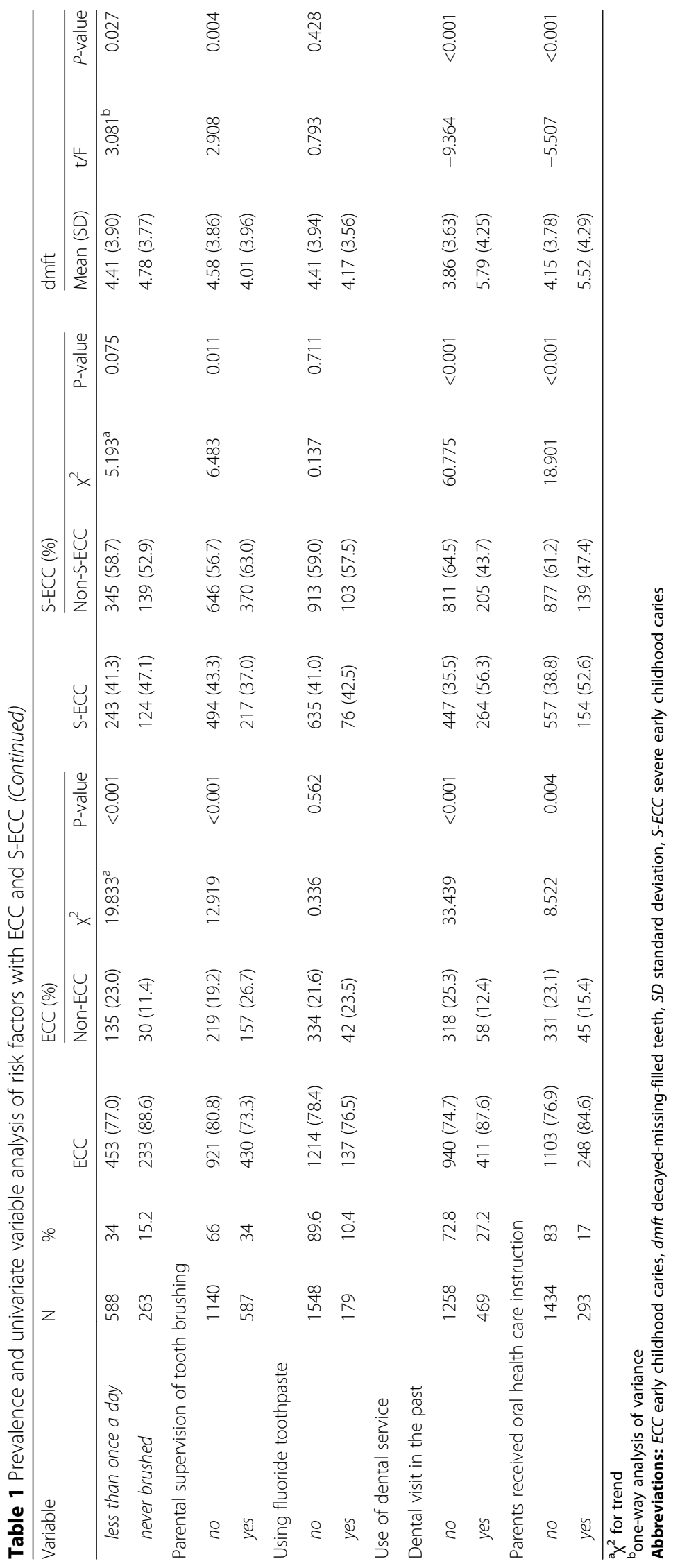


Table 2 Risk indicators for early childhood caries in multivariate analysis

\begin{tabular}{|c|c|c|c|c|c|c|c|}
\hline \multirow[t]{2}{*}{ Variable } & \multirow[t]{2}{*}{ B } & \multirow[t]{2}{*}{ SE } & \multirow[t]{2}{*}{ Wald $x^{2}$} & \multirow{2}{*}{$\begin{array}{l}P \text { - } \\
\text { value }\end{array}$} & \multirow[t]{2}{*}{ OR } & \multicolumn{2}{|l|}{$95 \% \mathrm{Cl}$} \\
\hline & & & & & & Lower & Upper \\
\hline Constant & 2.269 & 0.551 & 16.946 & $<0.001$ & 9.671 & & \\
\hline Region (reference, Kashgar) & 1.011 & 0.154 & 43.230 & $<0.001$ & 2.747 & 2.033 & 3.713 \\
\hline Age (years) & & & 30.310 & $<0.001$ & & & \\
\hline Age 1 & 0.737 & 0.167 & 19.428 & $<0.001$ & 2.090 & 1.506 & 2.901 \\
\hline Age 2 & 0.981 & 0.185 & 28.045 & $<0.001$ & 2.666 & 1.855 & 3.833 \\
\hline Caretaker with cavities (reference, no) & 0.577 & 0.183 & 9.975 & 0.002 & 1.780 & 1.245 & 2.547 \\
\hline Mother's education level (reference, none or primary) & -0.202 & 0.103 & 3.848 & 0.050 & 0.817 & 0.668 & 1.000 \\
\hline Father's education level (reference, none or primary) & 0.024 & 0.104 & 0.053 & 0.819 & 1.024 & 0.836 & 1.255 \\
\hline Annual family income & -0.404 & 0.070 & 33.713 & $<0.001$ & 0.667 & 0.582 & 0.765 \\
\hline Frequency of sweets consumption (reference, more than once) & -0.416 & 0.074 & 31.236 & $<0.001$ & 0.660 & 0.570 & 0.763 \\
\hline Eating before sleep (reference, often) & -0.584 & 0.125 & 21.960 & $<0.001$ & 0.557 & 0.437 & 0.712 \\
\hline Start tooth brushing (reference, $\leq 3$ years old) & 0.31 & 0.078 & 15.985 & $<0.001$ & 1.363 & 1.171 & 1.587 \\
\hline Daily brushing frequency (reference, less than once) & 0.036 & 0.136 & 0.071 & 0.789 & 1.037 & 0.795 & 1.353 \\
\hline Parental supervision of tooth brushing (reference, no) & -0.271 & 0.147 & 3.404 & 0.065 & 0.762 & 0.571 & 1.017 \\
\hline Dental visit in the past (reference, no) & 0.705 & 0.177 & 15.759 & $<0.001$ & 2.023 & 1.429 & 2.865 \\
\hline Parents having received oral health instruction (reference, no) & 0.775 & 0.209 & 13.717 & $<0.001$ & 2.171 & 1.440 & 3.272 \\
\hline
\end{tabular}

Age code: age of $3(0,0)$; age of $4(1,0)$; age of $5(0,1)$

Abbreviations: $\mathrm{Cl}$ confidence interval, $O R$ odds ratio, SE standard error

surveys from adjacent provinces $(71.4 \%$ in Qinghai, 73.8\% in Nei Mongol, 55.8\% in Gansu) [21], but also higher than that in surveys from neighboring developing countries, including Pakistan (43.7\%) [22], India (58.6\%) [23], and Nepal (52\%) [24]. Among those studies, an SECC prevalence of only 13\% was reported in Pakistan
[23]. Our prevalence of ECC is three times higher than that in Pakistan and is similar to the high prevalence of severe caries (44.1\%) reported in Northern Thailand [25]. Moreover, we found a high mean dmft of 5.61 for ECC and 8.17 for S-ECC, as well as a very low filling rate $(1.7 \%)$ among local preschool children.

Table 3 Risk indicators for severe early childhood caries in multivariate analysis

\begin{tabular}{|c|c|c|c|c|c|c|c|}
\hline \multirow[t]{2}{*}{ Variable } & \multirow[t]{2}{*}{$B$} & \multirow[t]{2}{*}{ SE } & \multirow[t]{2}{*}{ Wald $x^{2}$} & \multirow[t]{2}{*}{$P$-value } & \multirow[t]{2}{*}{ OR } & \multicolumn{2}{|l|}{$95 \% \mathrm{Cl}$} \\
\hline & & & & & & Lower & Upper \\
\hline Constant & 1.221 & 0.385 & 10.035 & 0.002 & 3.390 & & \\
\hline Age (years) & & & 3.611 & 0.164 & & & \\
\hline Age 1 & 0.282 & 0.149 & 3.577 & 0.059 & 1.326 & 0.990 & 1.776 \\
\hline Age 2 & 0.228 & 0.155 & 2.155 & 0.142 & 1.256 & 0.926 & 1.704 \\
\hline Caretaker with cavities (reference, no) & 0.602 & 0.125 & 23.204 & $<0.001$ & 1.827 & 1.43 & 2.334 \\
\hline Mother's education level (reference, none or primary) & -0.113 & 0.078 & 2.103 & 0.147 & 0.893 & 0.766 & 1.041 \\
\hline Father's education level (reference, none or primary) & -0.096 & 0.081 & 1.420 & 0.233 & 0.909 & 0.776 & 1.064 \\
\hline Annual family income & -0.171 & 0.053 & 10.452 & 0.001 & 0.843 & 0.760 & 0.935 \\
\hline Frequency of sweets consumption (reference, more than once) & -0.173 & 0.056 & 9.578 & 0.002 & 0.842 & 0.754 & 0.939 \\
\hline Eating before sleep (reference, often) & -0.366 & 0.097 & 14.108 & $<0.001$ & 0.694 & 0.573 & 0.840 \\
\hline Start tooth brushing (reference, $\leq 3$ years old) & -0.032 & 0.060 & 0.285 & 0.594 & 0.969 & 0.861 & 1.089 \\
\hline Daily brushing frequency (reference, less than once) & 0.064 & 0.102 & 0.389 & 0.533 & 1.066 & 0.873 & 1.301 \\
\hline Parental supervision of tooth brushing (reference, no) & -0.210 & 0.120 & 3.051 & 0.081 & 0.811 & 0.641 & 1.026 \\
\hline Dental visit in the past (reference, no) & 0.812 & 0.122 & 44.371 & $<0.001$ & 2.253 & 1.774 & 2.861 \\
\hline Parents having received oral health instruction (reference, no) & 0.599 & 0.149 & 16.074 & $<0.001$ & 1.821 & 1.358 & 2.441 \\
\hline
\end{tabular}


The current prevalence and treatment status of ECC highlight the fact that caries remains a serious and urgent problem among children in Xinjiang. In accordance with several known orcontroversial factors related to ECC and S-ECC identified in previous studies $[1,11,12$, $20]$, the prevalence of ECC is determined by a complex interaction between sociodemographic and behavioral factors. Lower sociodemographic status (region, less well-educated mother, low-income family, caregiver with cavities), risky dietary behavior (high-frequency sweets consumption, often eating before sleep), risky oral hygiene behavior (starting tooth brushing at an older age), and use of a dental service (dental visit in the past, parents had received oral health care instruction) were associated with ECC and S-ECC in the present study. Our study found that Ining (81.9\%) and Kashgar (74.8\%) children had a high prevalence of ECC and the prevalence was significantly different between the two regions. The higher caries rates of children in the two regions may reflect inequalities in socioeconomic conditions, an inadequate governmental oral health care system, limited human resources, poor behaviors, and limited awareness of oral health care measures. According to data from the Xinjiang Statistics Bureau in 2013 [17], local governmental health expenditure of 160.91 billion RMB accounted for $4.6 \%$ of the total health care budget, but the spending on oral health care was very low. Although there are no accurate statistics, it is likely that over $90 \%$ of total oral health expenditure in Xinjiang is not covered by basic medical insurance. Oral care services are paid for mainly by patients themselves. During the same year, the average annual income in Xinjiang was 13,585 RMB, and only 7296 RMB for a rural family, so most low-income families could not afford dental treatment, which may be one reason for the high caries and low filling rates in the region. People with a lower income and poor educational level usually have a relatively lower life expectancy, and children from low-income families are more likely to suffer from childhood illnesses [26]. Moreover, maternal education influences beliefs and attitudes towards the oral health care of children [15]. Mothers and caregivers play a role in cultivating children's dental health behavior, including tooth brushing, dental care, and dietary habits, which are acknowledged to be protective factors for the primary teeth $[15,20]$. Like in other studies $[13,15,27]$, the present study found negative associations of a more highly educated mother and a higher average annual income with ECC, and in contrast, there was a positive correlation between caregivers with cavities and caries rates.

Furthermore, the number of registered dentists in Xinjiang was 2573 in 2013 and the dentist to population ratio was only $1: 8800$, which is far below the average of approximately 1:2000 in most developing countries [1].
The shortage of dentists, particularly specialists in pediatric dentistry, is another important reason for the lack of treatment available for ECC in the less developed frontier provinces of China [28]. Further, risky dietary [6, 14] and poor oral hygiene $[11,15]$ behaviors have been found to be strongly associated with the prevalence of ECC. As reported in previous studies, we found that a low frequency of sweets consumption, no eating before sleep, and starting tooth brushing at a younger age had a significant negative relationship with the risk for caries. Fewer public oral health education initiatives have been undertaken by government medical organizations or individuals in the two study regions. Most parents and caretakers were unaware of their children's oral health status. Among the poorly educated Uygur parents, the language barrier added to their difficulty of accessing oral health information, which may be another reason for the severe caries status in their children. It would be helpful to provide information not only in Chinese but also in the native languages of minority groups when implementing dental health education strategies. Most parents did not focus on oral health care information until their children visited a dentist for severe toothache. Hence, we found that many children with ECC and S-ECC had made a dental visit in the past, because their parents had received oral health care instruction. Therefore, it seems that dentists do not play an effective role in caries prevention practices [11], probably because the demand for dental care is highly symptom-driven. This, together with the scarcity of dental health care services, may leave the dentist with little time and opportunity to provide preventive advice. These observations highlight the need for development of local oral health care policy to protect primary dentition, insurance reform to cover the field of oral preventive services, an improved oral health care system and health education for the public, more dentists in the rural regions, and promotion of the preventive role of dentists.

This study has some limitations, particularly its crosssectional design, which did not allow for investigation of a cause-effect relationship. Further, only a small number of subjects were selected from more than 10,000 eligible children. We tried to minimize this potential source of selection bias by enrolling children from as many kindergartens as possible in the two study regions. Further, we cannot exclude the possibility of a degree of response bias because the data from caregivers were retrospective and caregivers may have responded with the intention of pleasing the interviewer or been guided by them during the interview. Future research on this topic should include a longitudinal study design and a larger study population.

\section{Conclusion}

The findings of this study demonstrate that ECC and SECC remain a serious and urgent problem among 
preschool children in Xinjiang. Lower sociodemographic status (undeveloped region, a less educated mother, a low-income family, a caregiver with cavities), risky dietary behavior (high-frequency sweets consumption, often eating before sleep), risky oral hygiene behavior (starting tooth brushing at an older age), and use of a dental service (dental visit in the past, parents having received oral health care instruction) were associated with an increased risk of ECC and S-ECC. These factors could be modified by public health strategies, such as development of preventive strategies for primary dentition, reform of insurance to cover the field of oral preventive services, an improved oral health care system and health education for the public, more dentists in rural areas, and promotion of the role of dentists in prevention service.

\section{Additional file}

Additional file 1: Figure S1. The map of Xinjiang. The red tags indicate the geographic study areas. (DOCX 64 kb) (DOCX 64 kb)

\section{Abbreviations}

Cl: Confidence interval; dmft: decayed-missing-filled teeth; ECC: Early childhood caries; OR: Odds ratio

\section{Acknowledgments}

The authors thank the local governmental Bureau of Education for providing the data used in this investigation and gratefully acknowledge those who assisted with the study, including all participating parents and children.

\section{Funding}

This study was funded by the Xinjiang Uygur Autonomic Scientific and Technological Support Projects (grant number 201333105) and National Natural Science Foundation of China (grant number 81360167) projects. The funding agency had no role in the study design, the collection, analysis, or interpretation of data, the writing of the report, or the decision to submit the article for publication.

\section{Availability of data and materials}

The datasets used and/or analyzed during the current study are available from the corresponding author on reasonable request.

\section{Authors' contributions}

JZ conceived, coordinated, and supervised the study. YL and JW participated in the survey design, analyzed the data, and wrote the manuscript. AA and $Y L$ performed the dental examinations and contributed to interpretation of the results. All authors read and approved the final manuscript.

\section{Ethics approval and consent to participate}

This study was approved by the ethics committee at the First Affiliated Hospital of Xinjiang Medical University (Reference 20,130,216-103). Written informed consent was obtained from the children's caregivers before proceeding to a dental examination.

\section{Consent for publication}

$$
\text { Not applicable. }
$$

\section{Competing interests}

The authors declare that they have no competing interests

\section{Publisher's Note}

Springer Nature remains neutral with regard to jurisdictional claims in published maps and institutional affiliations.

\section{Author details}

'Department of Endodontics, the First Affiliated Hospital of Xinjiang Medical University, No. 137, Li Yu Shan South Road, Urumqi, Xinjiang Province 830054, China. ${ }^{2}$ Stomatology Disease Institute of Xinjiang Uyghur Autonomous Region, Urumqi, Xinjiang 830054, China.

Received: 22 December 2016 Accepted: 20 November 2017

Published online: 02 December 2017

\section{References}

1. Zhang X, Yang S, Liao Zh XL, Li C, Zheng H, et al. Prevalence and care index of early childhood caries in mainland China: evidence from epidemiological surveys during 1987-2013. Sci Rep. 2016;6:18897.

2. Benjamin RM. Oral health: the silent epidemic. Public Health Rep. 2010;125: 158-9.

3. Marcenes W, Kassebaum NJ, Bernabé E, Flaxman A, Naghavi M, Lopez A et al. Global burden of oral conditions in 1990-2010: a systematic analysis. Dent Res. 2013:92:592-7.

4. Naidu R, Nunn J, Forde M. Oral healthcare of preschool children in Trinidad: a qualitative study of parents and caregivers. BMC Oral Health. 2012;12:27. doi: 10.1186/1472-6831-12-27.

5. U.S. Department of Health and Human Services. Prevention of dental caries in children younger than 5 years old: systematic review to update the U.S. Preventive Services Task Force recommendation. Publication No.12-051 70-EF-1. Agency for Healthcare Research and Quality: Rockville, MD; 2014.

6. Masumo R, Bardsen A, Mashoto K, Åstrøm AN. Prevalence and sociobehavioral influence of early childhood caries, ECC, and feeding habits among 6-36 months old children in Uganda and Tanzania. BMC Oral Health. 2012;12:24

7. Sachdev J, Bansal K, Chopra R. Effect of comprehensive dental rehabilitation on growth parameters in pediatric patients with severe early childhood caries. Int J Clin Pediatr Dent. 2016;9:15-20.

8. American Academy on Pediatric Dentistry; American Academy of Pediatrics. Policy on early childhood caries (ECC): classifications, consequences and preventive strategies. Pediatr Dent. 2008-2009;30(7 Suppl):40-3.

9. Ismail Al, Sohn WA. Systematic review of clinical diagnostic criteria of early childhood caries. J Public Health Dent. 1999;59:172-91.

10. Doğan D, Dülgergil CT, Mutluay AT, Yıldııım I, Hamidi MM, Colak H. Prevalence of caries among preschool-aged children in a central Anatolian population. Nat Sci. Biol Med. 2013;4:325-9.

11. Nobile CGA, Fortunato L, Bianco A, Pileggi C, Pavia M. Pattern and severity of early childhood caries in southern Italy: a preschool-based cross-sectional study. BMC Public Health. 2014;14:206.

12. Peltzer K, Mongkolchati A. Severe early childhood caries and social determinants in three-year-old children from northern Thailand: a birth cohort study. BMC Oral Health. 2015;15:108.

13. Schroth RJ, Halchuk S, Star L. Prevalence and risk factors of caregiver reported severe early childhood caries in Manitoba first nations children results from the RHS phase 2 (2008-2010). Int J Circumpolar Health. 2013;5, 72 doi: 10.3402/ijch.v72i0.21167.

14. Evans EW, Hayes C, Palmer CA, Bermudez Ol, Cohen SA, Must A. Dietary intake and severe early childhood caries in low-income, young children. J Acad Nutr Diet. 2013;113:1057-61. https://doi.org/10.1016/j.jand.2013.03.014.

15. Tiwari T, Quissell DO, Henderson WG, Thomas JF, Bryant LL, et al. Factors associated with oral health status in American Indian children. J Racial Ethn Health Disparities. 2014;1:148-56.

16. Custodio-Lumsden CL, Wolf RL, Contento IR, Basch CE, Zybert PA, Koch PA, et al. Validation of an early childhood caries risk assessment tool in a lowincome Hispanic population. J Public Health Dent. 2016;76:136-42. https:// doi.org/10.1111/ jphd.12122.

17. Statistics Bureau of Xinjiang Uygur Autonomous Region. Xinjiang statistical Yearbook-2014. Beijing: China Statistics Press; 2014.

18. Cai TH, Maimaiti Y, He HY, Li LH, Tian Y, Gu ZY, et al. Epidemiological investigation of dental caries among 12-year-old children in northern Xinjiang. Journal of Xinjiang Medical University. 2014;37:366-8.

19. World Health Organization. Oral health survey: basic methods. 4th ed Geneva: World Health Organization; 1997.

20. Ashkanani F, Al-Sane M. Knowledge, attitudes and practices of caregivers in relation to oral health of preschool children. Med Princ Pract 2013;22:167-72 
21. Qi XQ. Report of the third National Survey of oral health. Beijing: People's Medical Publishing House; 2008.

22. Dawani N, Nisar N, Khan N, Syed S, Tanweer N. Prevalence and factors related to dental caries among pre-school children of Saddar town, Karachi, Pakistan: a cross-sectional study. BMC Oral Health. 2012;12:59. doi: 10.1186/ 1472-6831-12-59.

23. Simratvir M, Moghe GA, Thomas AM, Singh N, Chopra S. Evaluation of caries experience in 3-6-year-old children, and dental attitudes amongst the caregivers in the Ludhiana city. J Indian Soc Pedod Prev Dent. 2009;27:164-9.

24. Prasai Dixit L, Shakya A, Shrestha M, Shrestha A. Dental caries prevalence, oral health knowledge and practice among indigenous Chepang school children of Nepal. BMC Oral Health. 2013;13:20. doi: 10.1186/1472-6831-13-20.

25. Peltzer K, Mongkolchati A. Severe early childhood caries and social determinants in three-year-old children from northern Thailand: a birth cohort study. BMC Oral Health. 2015;15:108. doi: 10.1186/s12903-015-0093-8.

26. Kunst AE. Describing socioeconomic inequalities in health in European countries: an overview of recent studies. Rev Epidemiol Sante Publique. 2007:55:3-11.

27. Wulaerhan J, Abudureyimu A, Bao XL, Zhao J. Risk determinants associated with early childhood caries in Uygur children: a preschool-based crosssectional study. BMC Public Health. 2014;14:136.

28. Chu CH, Lo ECM. Dental caries prevention and treatment for preschool children in China. Chin J Dent Res. 2007;10(Suppl):54-60.

Submit your next manuscript to BioMed Central and we will help you at every step:

- We accept pre-submission inquiries

- Our selector tool helps you to find the most relevant journal

- We provide round the clock customer support

- Convenient online submission

- Thorough peer review

- Inclusion in PubMed and all major indexing services

- Maximum visibility for your research

Submit your manuscript at www.biomedcentral.com/submit
Biomed Central 